Rev. Bras. Saúde Prod. Anim., Salvador, v.13, n.1, p.110-122 jan/mar, 2012 http://www.rbspa.ufba.br ISSN 15199940

\title{
Níveis de Caroço de algodão na dieta de cordeiros confinados ${ }^{1}$
}

\author{
Whole cottonseed levels in feedlot lambs diets
}

\author{
PIONA, Maurício Nobuyuki Miyashita ${ }^{2 *}$; CABRAL, Luciano da Silva ${ }^{3}$; \\ ZERVOUDAKIS, Joanis Tilemahos ${ }^{3}$; ABREU, Joadil Gonçalves de ${ }^{3}$; GALATI, \\ Rosemary Lais ${ }^{3}$; CAETANO, Géssy Gabriela Gentile de Paula ${ }^{4}$; SILVA, Antonio \\ Rodrigues $\mathrm{da}^{2}$
}

\footnotetext{
${ }^{1}$ Parte da dissertação de mestrado do primeiro autor.

${ }^{2}$ Universidade Federal de Mato Grosso, Faculdade de Agronomia, Medicina Veterinária e Zootecnia, Departamento de Produção Animal, Rondonópolis, Mato Grosso, Brasil.

${ }^{3}$ Universidade Federal de Mato Grosso, Faculdade de Agronomia, Medicina Veterinária e Zootecnia, Programa de Pós-Graduação em Ciência Animal, Rondonópolis, Mato Grosso, Brasil.

${ }^{4}$ Médica Veterinária, Bolsista de Desenvolvimento Tecnológico e Industrial do CNPq.

*Endereço para correspondência: mauriciopiona@gmail.com
}

\section{RESUMO}

Objetivou-se indicar níveis adequados da inclusão do caroço de algodão em dietas de cordeiros em confinamento. Foram realizados dois experimentos: no primeiro foram utilizados cinco ovinos fistulados no rúmen, distribuídos em um delineamento em quadrado latino $5 \times 5$, e avaliadas dietas ausentes e com $7 ; 14 ; 21$ e $28 \%$ de inclusão de caroço de algodão. No segundo experimento foram utilizados 24 cordeiros com $27,3 \mathrm{~kg}$ de peso corporal inicial para avaliação do desempenho, e foram avaliadas dietas ausentes e com 10;20 e $30 \%$ de inclusão do caroço de algodão. As dietas continham uma relação volumoso:concentrado de 50:50, nas quais a silagem de milho foi utilizada como volumoso. Não foram observados efeitos da inclusão dos níveis de caroço de algodão sobre o consumo de matéria seca e matéria orgânica. Os consumos de fibra em detergente neutro e extrato etéreo foram aumentados, bem como o $\mathrm{pH}$ ruminal foi aumentado linearmente com a inclusão do caroço de algodão à dieta. Contrariamente, a concentração de nitrogênio amoniacal ruminal foi reduzida linearmente com a inclusão do caroço de algodão à dieta. $\mathrm{O}$ aumento da porcentagem de caroço de algodão à dieta reduziu linearmente o ganho de peso. Sugere-se a inclusão do caroço de algodão na dieta de ovinos em confinamento até o nível de $10 \%$.

Palavras-chave: desempenho, digestibilidade, ingestão, parâmetros ruminais, nutrientes

\section{SUMMARY}

The objective was to indicate appropriate inclusion levels of of whole cottonseed in feedlot lambs diets. Two experiments were conducted: in the first were used five rumen fitted sheep distributed in a 5x5 Latin square design, in which were evaluated diets absent and with 7; 14, 21 and 28\% inclusion of whole cottonseed. In the second experiment, 24 lambs were used with $27.3 \mathrm{~kg}$ of initial body weight, to assess the performance, in order to evaluate diets absent and with 10;20 and $30 \%$ inclusion of whole cottonseed. Diets containing a forage:concentrate ratio of 50:50, were used the corn silage utilized as roughage. There were no effects of the inclusion levels of whole cottonseed on intake of dry matter and organic matter. The intake of NDF and EE were increased, and ruminal $\mathrm{pH}$ was increased linearly with the addition of whole cottonseed on the diet. In contrast, the concentration of rumen ammonia nitrogen was reduced linearly with the addition of whole cottonseed on the diet. The increase of the percentage of whole cottonseed to the diet linearly reduced lambs weight gain. The whole cottonseed can be used to feedlot sheep up to $10 \%$ of inclusion levels in diets.

Keywords: digestibility, intake, nutrients, performance, rumen parameters 


\section{INTRODUÇ̃̃̃O}

Ao se considerar que cerca de metade da carne ovina consumida no Brasil é importada do Uruguai, Argentina e Chile (SANTOS et al., 2008), torna-se premente a necessidade de adoção de tecnologias na atividade com o intuito de incrementar a produção de carne. Desta forma, o confinamento de cordeiros representa estratégia viável para produzir carne ovina de forma intensiva e de elevada qualidade. Dentro deste enfoque, $o$ uso de ingredientes alternativos ao milho e farelo de soja para ovinos em confinamento pode reduzir os custos da dieta e aumentar a margem de lucro do produtor (SANTOS et al., 2010).

O estado de Mato Grosso é o maior produtor de algodão do Brasil (2,384 mil t/ano), o que proporciona uma elevada disponibilidade do caroço de algodão para uso na alimentação animal (CONAB, 2009). Entretanto, deve-se ressaltar que é de fundamental importância o conhecimento das propriedades físicas e químicas deste co-produto, uma vez que ele possui distintas características de degradação e passagem pelo trato gastrintestinal, quando comparado com forragens e ou alimentos comumente utilizados na formulação de rações para ruminantes. Estas peculiaridades podem afetar o consumo, que é influenciado pela estrutura física e composição das dietas (CARVALHO et al., 2004).

Os valores de consumo e a digestibilidade aparente de um alimento são importantes na determinação do seu valor nutritivo, pois é por intermédio dessas variáveis que é possível o cálculo da quantidade dos nutrientes ingeridos e a proporção dos nutrientes disponível para uso pelo animal, para as funções de mantença e produção (NRC, 2001).
O desempenho animal é função do consumo diário de matéria seca, da composição da dieta e da digestibilidade dos seus nutrientes. Desta forma, a avaliação de ingredientes alternativos com potencial de uso na dieta de ruminantes deve prever os efeitos desses alimentos sobre o consumo, a digestibilidade e o desempenho animal (SANTOS et al., 2010).

Como maneira de avaliar o balanceamento de proteína na dieta dos animais, pode-se utilizar a determinação da concentração de amônia ruminal como parâmetro, de forma que quando são observadas elevadas concentrações $(>20 \mathrm{mg} / \mathrm{dL})$, pode-se inferir que houve excesso de proteína degradada no rúmen e/ou a reduzida concentração de carboidratos fermentáveis (CAVALCANTE et al., 2005). Neste contexto, objetivou-se com este experimento indicar os níveis de inclusão do caroço de algodão em dietas para ovinos em confinamento.

\section{MATERIAL E MÉTODOS}

O experimento foi realizado no Setor de Ovinocultura da Fazenda Experimental da Faculdade de Agronomia e Medicina Veterinária, da Universidade Federal de Mato Grosso (UFMT), localizada no município de Santo Antônio de Leverger, distante $30 \mathrm{~km}$ de Cuiabá-MT. O local do experimento encontra-se na altitude $141 \mathrm{~m}$, Latitude $15^{\circ} 51^{\prime}$ Sul, Longitude $56^{\circ} 04^{\prime}$ ' Oeste e clima tropical semiúmido. $\mathrm{O}$ ensaio teve 70 dias de duração, teve início no dia 8/01/2009 e o encerramento no dia 19/03/2009.

Foram realizados dois experimentos: no primeiro, foram utilizados cinco ovinos da raça Santa Inês fistulados no rúmen, castrados, com peso médio inicial de $51,3 \mathrm{~kg}$. O delineamento experimental 
utilizado foi o quadrado latino (5X5), e os tratamentos consistiram de cinco níveis de inclusão do caroço de algodão (ração ausente e com $7 ; 14 ; 21$ e $28 \%$ com base na matéria seca) e cinco períodos de avaliação. Cada período teve duração de 14 dias, dos quais os 10 primeiros dias de cada período destinados à adaptação dos animais aos tratamentos e os quatro dias finais às coletas de amostras de fezes e líquido ruminal.
As baias destinadas aos animais tinham dimensões de $1,8 \mathrm{~m} \times 1,0 \mathrm{~m} \times 1,5 \mathrm{~m}$, as quais eram feitas de madeira, suspensas e com piso ripado, cobertas e providas de bebedouros e comedouros de plástico.

Os concentrados foram isoproteicos, continham $22 \pm 1 \%$ de proteína Bruta (PB) (Tabela 1), e a dieta total composta por silagem de milho (50\%) e concentrado $(50 \%)$. A dieta foi fornecida duas vezes ao dia, às $09 \mathrm{~h}$ e $16 \mathrm{~h}$, de modo a proporcionar sobras diárias de $10 \%$.

Tabela 1. Composição percentual dos concentrados, com base na matéria natural, e teores dos nutrientes

\begin{tabular}{|c|c|c|c|c|c|}
\hline \multirow{2}{*}{ Ingredientes $(\mathrm{Kg})$} & \multicolumn{5}{|c|}{ Níveis de inclusão do caroço de algodão na dieta } \\
\hline & 0 & 7 & 14 & 21 & 28 \\
\hline Milho grão triturado & 68,0 & 61,5 & 54,5 & 46,5 & 37,5 \\
\hline Farelo de soja & 28,0 & 20,0 & 13,0 & 7,0 & 2,0 \\
\hline Ureia + sulfato de amônio $(9: 1)$ & 1,0 & 1,5 & 1,5 & 1,5 & 1,5 \\
\hline Mistura mineral $^{1}$ & 3,0 & 3,0 & 3,0 & 3,0 & 3,0 \\
\hline \multirow[t]{2}{*}{ Caroço de algodão } & 0,0 & 14,0 & 28,0 & 42,0 & 56,0 \\
\hline & \multicolumn{5}{|c|}{ Composição bromatológica } \\
\hline Matéria seca (\%) & 88,31 & 88,70 & 89,05 & 89,41 & 89,78 \\
\hline Matéria orgânica (\%) & 93,69 & 93,90 & 94,05 & 94,16 & 94,22 \\
\hline Proteína bruta $(\%)$ & 22,67 & 22,76 & 21,87 & 21,38 & 21,29 \\
\hline Extrato etéreo (\%) & 3,26 & 5,50 & 7,74 & 9,95 & 12,15 \\
\hline Fibra em detergente neutro (\%) & 13,60 & 17,97 & 22,41 & 26,86 & 31,32 \\
\hline
\end{tabular}

${ }^{\mathrm{T}}$ Mistura mineral comercial para ovinos.

Do $11^{0}$ ao $13^{0}$ dia de cada período experimental, amostras da silagem de milho, concentrado, sobras e fezes foram coletadas para posterior análise. $\mathrm{O}$ consumo foi determinado pela diferença entre a quantidade ofertada e a respectiva sobra. As amostras de fezes foram coletadas duas vezes ao dia, às $09 \mathrm{~h} 15 \mathrm{~min}$ e $15 \mathrm{~h}$, diretamente da ampola retal, armazenadas em sacos de plásticos devidamente identificados e acondicionados em freezer para análises laboratoriais ao término do experimento.

Para determinação dos valores de $\mathrm{pH}$ e da concentração de nitrogênio amoniacal no fluido ruminal, amostras foram coletadas manualmente no $14^{\circ}$ dia do período experimental, imediatamente antes da alimentação da manhã e quatro horas após, ou seja às 08h30min e $13 \mathrm{~h}$, respectivamente, na região de interface líquido/sólido do ambiente ruminal e filtradas em camada tripla de gaze. A mensuração do $\mathrm{pH}$ foi 
realizada imediatamente após a coleta por intermédio de peagâmetro digital. Para a determinação de amônia foi separada uma alíquota de $50 \mathrm{~mL}$ de líquido ruminal, e adicionado $1 \mathrm{~mL}$ de solução de $\mathrm{HCl} 1: 1$, posteriormente acondicionada em recipiente plástico com tampa, identificada e congelada $\left(-20^{\circ} \mathrm{C}\right)$ para preservação e posteriores análises laboratoriais.

No segundo experimento, foram utilizados 24 cordeiros deslanados SPRD (sem padrão de raça definida), não castrados, com idade média de cinco meses e peso vivo inicial de $27,3 \mathrm{~kg}$. Utilizou-se delineamento inteiramente casualizado com quatro tratamentos (rações ausentes e com 10; 20 e 30\% de inclusão do caroço de algodão) e seis repetições por tratamento. Em função da estrutura do galpão, foi possível avaliar apenas quatro níveis de inclusão do caroço de algodão na dieta. Inicialmente, os animais foram casqueados, vacinados contra clostridiose, identificados e tratados contra endoparasitos.

As dietas eram compostas por silagem de milho $(50 \%)$ e concentrado $(50 \%)$, este último continha fubá de milho, farelo de soja, ureia e mistura mineral, além de caroço de algodão (CA) nos níveis zero $10 ; 20$ e $30 \%$ de inclusão (Tabela 2). A dieta era ofertada duas vezes ao dia, às $09 \mathrm{~h}$ e às $16 \mathrm{~h}$, de modo a proporcionar sobras diárias de $10 \%$ do ofertado, que eram pesadas diariamente antes do primeiro trato.

Tabela 2. Composição percentual das rações na matéria natural e teores dos nutrientes

\begin{tabular}{lcccc}
\hline \multirow{2}{*}{ Ingredientes (\%) } & \multicolumn{5}{c}{ Níveis de inclusão do caroço de algodão na dieta } \\
\cline { 2 - 5 } & 0 & 10 & 20 & 30 \\
\hline Milho em grão triturado & 68 & 59,5 & 47,5 & 35,5 \\
Farelo de foja & 28 & 16 & 8 & 0 \\
Ureia + sulfato de amônio (9:1) $^{\text {Mistura mineral }}{ }^{1}$ & 1 & 1,5 & 1,5 & 1,5 \\
Misto de algodão $_{\text {Caroço de }}$ & 3 & 3 & 3 & 3 \\
\hline & 0 & 20 & 40 & 60 \\
\hline Matéria seca & \multicolumn{5}{c}{ Composição bromatológica (\%) } \\
Matéria orgânica & 88,31 & 88,84 & 89,36 & 89,89 \\
Proteína bruta & 93,69 & 94,01 & 94,14 & 94,26 \\
Extrato etéreo & 21,18 & 21,26 & 21,44 & 21,62 \\
Fibra em detergente neutro & 3,26 & 6,48 & 9,63 & 12,78 \\
\hline
\end{tabular}

${ }^{1}$ Mistura mineral própria para ovinos.

O galpão destinado aos animais para a avaliação do desempenho e consumo era constituído por baias coletivas de 3 x $9 \mathrm{~m}$, com parte cimentada e coberta, e solário com piso batido, providos de bebedouros de cimento com bóia e comedouros de plástico. No início e final do experimento os animais foram pesados, após jejum de sólidos de 16 horas, para avaliar o ganho médio diário de peso (GMD). As pesagens intermediárias, foram realizadas a cada 
21 dias, a fim de possibilitar o acompanhamento do desenvolvimento dos animais.

Ao término do experimento as amostras dos volumosos, sobras e fezes foram encaminhadas ao Laboratório, onde foram descongeladas e homogeneizadas para obtenção das amostras compostas por tratamento. As amostras foram présecas em estufas de ventilação forçada a $60 \pm 5^{\circ} \mathrm{C}$, por 72 horas, e em seguida, moídas em moinho tipo Willey, mediante utilização de peneiras com malha de um milímetro.

Essas amostras foram submetidas à determinação da matéria seca (MS), proteína bruta $(\mathrm{PB})$, extrato etéreo $(\mathrm{EE})$ e matéria mineral (MM), de acordo com as metodologias compiladas em Silva \& Queiroz (2004) e, da fibra em detergente neutro (FDN), conforme Van Soest et al. (1991). Os carboidratos totais (CT) foram obtidos pela seguinte equação $\mathrm{CT}=100-(\% \mathrm{~PB}+\% \mathrm{MM}+$ $\%$ EE), de acordo com Cabral et al. (2006).

Para determinação da fibra em detergente neutro indigestível (FDNi), que foi utilizada como indicador interno para estimativa da excreção fecal, as amostras dos volumosos, concentrados, caroço de algodão, sobras e fezes foram acondicionadas em sacos de nylon e incubadas no rúmen através de uma cânula ruminal, de um bovino SPRD com peso médio de $450 \mathrm{~kg}$ por 144 horas (BERCHIELLI et al., 2000).

$\mathrm{O}$ material remanescente da incubação foi submetido à análise para determinação de FDN. Desta forma, a excreção fecal da matéria seca foi calculada pela relação entre o consumo de FDNi (g) e a sua respectiva porcentagem nas amostras fecais. Uma vez obtida a excreção fecal da matéria seca, foi calculada a excreção fecal dos demais nutrientes, pela multiplicação da primeira pela concentração destes nas fezes. Assim, o coeficiente de digestibilidade aparente (\%) da matéria seca e dos demais nutrientes foi obtido pela relação entre o consumo destes e a sua excreção fecal, multiplicado por 100 (BERCHIELLI et al., 2000).

Os dados de consumo, digestibilidade, $\mathrm{pH}$ e nitrogênio amoniacal ruminal foram submetidos à análise de variância e regressão, considerando um delineamento em quadrado latino (5X5), com significância de $5 \%$, por meio do programa SAEG (UFV, 2001), por meio do seguinte modelo estatístico:

$\mathrm{Y}_{\mathrm{ijkl}}=\mu+\mathrm{NC}_{\mathrm{i}}+\mathrm{P}_{\mathrm{j}}+\mathrm{A}_{\mathrm{k}}+\mathrm{e}_{\mathrm{ijk}}$ em que:

$\mathrm{Y}_{\mathrm{ijk}}=$ observação referente ao animal $\mathrm{k}$ submetido ao nível i de caroço de

algodão;

$\mu=$ média geral;

$\mathrm{NC}_{\mathrm{i}}=$ efeito referente ao i-ésimo nível de caroço de algodão;

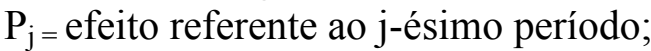

$A_{k}=$ efeito referente ao k-ésimo animal;

$\mathrm{e}_{\mathrm{ijk}}=$ erro aleatório pressuposto NID.

Os dados de ganho de peso foram analisados ao considerar delineamento inteiramente casualizado. A escolha do modelo de regressão foi realizada conforme os valores de $\mathrm{P}$ e $\mathrm{R}^{2}$. Ao se ter em conta que no primeiro experimento foram testados cinco níveis de caroço de algodão, os efeitos linear, quadrático e cúbico foram testados, enquanto que no experimento de desempenho apenas foram testados os modelos linear $\mathrm{e}$ quadrático, com base nos graus de liberdade em cada experimento.

\section{RESULTADOS E DISCUSSÃO}

Os valores médios para os consumos dos nutrientes em função das dietas estão dispostos na Tabela 3, onde pode ser notado que o incremento dos níveis de caroço de algodão na dieta de ovinos 
Rev. Bras. Saúde Prod. Anim., Salvador, v.13, n.1, p.110-122 jan/mar, 2012 http://www.rbspa.ufba.br ISSN 15199940

não afetou o consumo de matéria seca (CMS) e matéria orgânica (CMO), mas o consumo de proteína bruta (CPB) reduziu em $0,001231 \mathrm{~kg} /$ dia para cada $1 \%$ de caroço de algodão incluso à dieta (Tabela 3).

Diferentemente do observado para o $\mathrm{CPB}$, houve aumento nos consumo de extrato etéreo (CEE) e FDN em 0,001465 e $0,002049 \mathrm{~kg} /$ dia para cada $1 \%$ de caroço de algodão acrescentado à dieta (Tabela 3), o que pode ser explicado pelo maior percentual de EE $(17,85 \%)$ e FDN $(53,17 \%)$ no caroço de algodão comparado ao milho e farelo de soja.

Tabela 3. Valores médios para os consumos de matéria seca, matéria orgânica, proteína bruta, extrato etéreo, carboidratos totais e fibra em detergente neutro em função das dietas

\begin{tabular}{|c|c|c|c|c|c|c|c|c|}
\hline \multirow{2}{*}{ Variável } & \multicolumn{5}{|c|}{ caroço de algodão na dieta (\% MS) } & \multirow{2}{*}{$\mathrm{P}$} & \multirow{2}{*}{ EPM } & \multirow{2}{*}{$\mathrm{R}^{2}$} \\
\hline & 0 & 7 & 14 & 21 & 28 & & & \\
\hline $\mathrm{CMS}^{1}(\mathrm{~kg} / \mathrm{dia})$ & 1,008 & 1,108 & 1,056 & 1,014 & 0,938 & ns & 0,028 & - \\
\hline $\mathrm{CMO}^{2}(\mathrm{~kg} / \mathrm{dia})$ & 0,954 & 1,050 & 1,007 & 0,969 & 0,882 & ns & 0,028 & - \\
\hline $\mathrm{CPB}^{3}(\mathrm{~kg} / \mathrm{dia})$ & 0,169 & 0,185 & 0,171 & 0,154 & 0,137 & $0,0013 * *$ & 0,008 & 0,70 \\
\hline $\mathrm{CEE}^{4}(\mathrm{~kg} / \mathrm{dia})$ & 0,032 & 0,046 & 0,059 & 0,069 & 0,079 & $0,0000^{* *}$ & 0,008 & 0,98 \\
\hline $\mathrm{CCT}^{5}(\mathrm{~kg} / \mathrm{dia})$ & 0,753 & 0,819 & 0,777 & 0,746 & 0,666 & ns & 0,002 & - \\
\hline $\mathrm{CFDN}^{6}(\mathrm{~kg} / \mathrm{dia})$ & 0,316 & 0,372 & 0,392 & 0,410 & 0,415 & $0,0094 * *$ & 0,018 & 0,84 \\
\hline $\mathrm{CMS}^{7}(\%$ do PC) & 1,97 & 2,17 & 2,08 & 2,00 & 1,84 & ns & 0,055 & - \\
\hline $\mathrm{CFDN}^{8}(\%$ do PC) & 0,62 & 0,73 & 0,78 & 0,81 & 0,81 & $0,0101 *$ & 0,036 & 0,83 \\
\hline
\end{tabular}

$\mathrm{CMS}=$ consumo de matéria seca, $\mathrm{CMO}=$ consumo de matéria orgânica, $\mathrm{CPB}=$ consumo de proteína bruta, $\mathrm{CEE}=$ consumo de extrato etéreo, $\mathrm{CCT}=$ consumo de carboidratos totais, $\mathrm{CFDN}=$ consumo de FDN.

$\mathrm{P}=$ probabilidade, $\mathrm{EPM}=$ erro padrão da média.

${ }^{1} \hat{\mathrm{Y}}=1,025 ;{ }^{2} \hat{\mathrm{Y}}=0,973 ;{ }^{3} \hat{\mathrm{Y}}=0,182-0,001231 * * \mathrm{CA} ;{ }^{4} \hat{\mathrm{Y}}=0,0344+0,001465 * * \mathrm{CA} ;{ }^{5} \hat{\mathrm{Y}}=0,752 ;$ ${ }^{6} \hat{\mathrm{Y}}=0,3357+0,002049 * * \mathrm{CA} ;{ }^{7} \hat{\mathrm{Y}}=2,01 ;{ }^{8} \hat{\mathrm{Y}}=0,6582+0,005923 * \mathrm{CA}$.

Resultados semelhantes foram obtidos por Cunha et al. (2008), Véras et al. (2005) e Rodrigues et al. (2003) para o consumo de FDN, os quais observaram que o acréscimo no nível de caroço de algodão à dieta acarretou em aumento no consumo de FDN, uma vez que este ingrediente possui elevado teor de FDN.

Não foi observado efeito dos níveis de caroço de algodão sobre o CMS quando este foi expresso em porcentagem do peso corporal, com média de $2,01 \%$ do PC. Contrariamente, o consumo de FDN (CFDN) foi aumentado em 0,005923 unidades percentuais para cada $1 \%$ de $\mathrm{CA}$ incluso à dieta (Tabela 3). Com base no CFDN, em porcentagem do peso corporal, pode-se inferir que o consumo não foi limitado pela repleção ruminal, pois se manteve inferior ao valor de $1,2 \%$ do PC (NRC, 2001).

A FDN representa a fração dos alimentos que apresenta lenta e incompleta digestão e ocupa espaço gastrintestinal dos animais ruminantes. Em dietas com maiores teores de FDN espera-se algum efeito sobre o consumo e ou digestibilidade. Uma vez que a digestibilidade ruminal da FDN é mais lenta que a dos CNF, inferese que possivelmente ocorrerá menor 
Rev. Bras. Saúde Prod. Anim., Salvador, v.13, n.1, p.110-122 jan/mar, 2012 http://www.rbspa.ufba.br ISSN 15199940

produção de proteína microbiana em animais que consumiam essas dietas, ou a síntese de células microbianas será menos eficiente. Ao se considerar que não há limitação de compostos nitrogenados no rúmen, a energia passa a ser o principal fator limitante em condições tropicais e, desta forma, uma vez que ela é proveniente da FDN, a disponibilidade de energia ocorrerá de forma lenta, isso limita a taxa de crescimento dos microorganismos no rúmen.

Cada $1 \%$ de caroço de algodão acrescido à dieta promoveu redução na digestibilidade da MS, MO, PB e CT em 0,$6407 ; 0,5978 ; 0,6244$ e $0,7118 \%$, respectivamente, enquanto a digestibilidade do EE foi aumentada em $0,233 \%$ para cada $1 \%$ de caroço de algodão. Em decorrência da menor digestão da MS, MO, PB e CT, ocorreu redução no teor de NDT da dieta em
$0,3909 \%$ para cada $1 \%$ de caroço de algodão (Tabela 4).

O aumento no coeficiente de digestibilidade aparente do EE com o aumento da conversão alimentar pode ser atribuído à redução da proporção do EE endógeno fecal em relação ao EE consumido, pois é sabido que a digestibilidade aparente de qualquer nutriente é função do seu consumo e da sua excreção fecal. Nutrientes presentes em baixas concentrações na dieta, mas que apresentem relativa contribuição endógena tendem a apresentar reduzida digestibilidade aparente (CABRAL et al., 2006). Os valores de digestibilidade aparente para o EE estão de acordo com os observados por Oliveira et al. (2009), Silva et al. (2007) e Santos et al. (2010), que ao trabalharem com dietas que continham fontes lipídicas, observaram coeficientes de digestibilidade de 85,74, 84,45 e $89,23 \%$, respectivamente.

Tabela 4. Valores médios para os coeficientes de digestibilidade da matéria seca, matéria orgânica, proteína bruta, extrato etéreo, carboidratos totais, fibra em detergente neutro e nutrientes digestíveis totais, em função das dietas

\begin{tabular}{|c|c|c|c|c|c|c|c|c|}
\hline \multirow{2}{*}{ Variável } & \multicolumn{5}{|c|}{ caroço de algodão na dieta (\% MS) } & \multirow{2}{*}{$\mathrm{P}$} & \multirow{2}{*}{ EPM } & \multirow{2}{*}{$\mathrm{R}^{2}$} \\
\hline & 0 & 7 & 14 & 21 & 28 & & & \\
\hline DAMS $^{1}$ & 70,59 & 60,84 & 57,66 & 56,78 & 47,41 & 0,0000 & 3,73 & 0,93 \\
\hline $\mathrm{DAMO}^{2}$ & 73,21 & 64,36 & 61,50 & 61,09 & 51,39 & 0,0000 & 3,50 & 0,92 \\
\hline $\mathrm{DAPB}^{3}$ & 76,55 & 70,98 & 68,48 & 65,12 & 54,97 & 0,0000 & 3,59 & 0,95 \\
\hline $\mathrm{DAEE}^{4}$ & 81,89 & 81,75 & 85,48 & 87,83 & 88,13 & 0,0006 & 1,38 & 0,89 \\
\hline $\mathrm{DACT}^{5}$ & 72,09 & 61,87 & 58,13 & 57,66 & 46,26 & 0,0000 & 4,15 & 0,92 \\
\hline $\mathrm{DFDN}^{6}$ & 52,96 & 43,78 & 42,19 & 43,47 & 37,62 & 0,0099 & 2,50 & 0,78 \\
\hline $\mathrm{NDT}^{7}$ & 76,65 & 68,86 & 67,84 & 69,01 & 61,29 & 0,0007 & 2,44 & 0,81 \\
\hline
\end{tabular}

DAMS = digestibilidade aparente da matéria seca, DAMO = digestibilidade aparente da matéria orgânica, $\mathrm{DAPB}=$ digestibilidade aparente da proteína bruta, DAEE = digestibilidade aparente do extrato etéreo, DACT = digestibilidade aparente dos carboidratos totais, DFDN = digestibilidade aparente da FDN, $\mathrm{NDT}=$ nutrientes digestíveis totais.

$\mathrm{P}=$ probabilidade, $\mathrm{EPM}=$ erro padrão da média.

${ }^{1} \hat{\mathrm{Y}}=68,53-0,6407 * * \mathrm{CA} ;{ }^{2} \hat{\mathrm{Y}}=71,52-0,5978^{* *} \mathrm{CA} ;{ }^{3} \hat{\mathrm{Y}}=76,84-0,6244 * * \mathrm{CA} ;{ }^{4} \hat{\mathrm{Y}}=81,43+$ $0,233 * * \mathrm{CA} ;{ }^{5} \hat{\mathrm{Y}}=70,16-0,7118^{* *} \mathrm{CA} ;{ }^{6} \hat{\mathrm{Y}}=50,06-0,3933 * * \mathrm{CA} ;{ }^{7} \hat{\mathrm{Y}}=74,75-0,3909 * * \mathrm{CA}$. 
Houve redução da digestibilidade da FDN com o acréscimo de caroço de algodão, que ocorreu em 0,3933\% para cada $1 \%$ de caroço de algodão. Este comportamento pode ser explicado pelo aumento no teor de EE na dieta em virtude da participação do caroço de algodão, cujo percentual em relação ao CMS foi de 3,$17 ; 4,15 ; 5,59 ; 6,80$; $8,44 \%$, para as dietas com zero, sete, 14 , 21 e $28 \%$ de caroço de algodão. Ao se considerar que na dieta de ruminantes o teor máximo de EE recomendado para minimizar os efeitos negativos na digestão da fibra é de $6 \%$, pode-se afirmar que as dietas com os níveis de 21 e $28 \%$ de caroço de algodão apresentavam teores de EE acima do recomendado, o que explica a redução da digestão da FDN. O NDT da dieta foi reduzido em 0,3909 unidades percentuais para cada $1 \%$ de $\mathrm{CA}$, pois ocorreu redução na digestão da $\mathrm{PB}, \mathrm{CT}$ e FDN.

Conforme NRC (2001), a produção de proteína microbiana é estimada a partir do NDT, em que, cada $1 \mathrm{~kg}$ de NDT propicia o fluxo de $130 \mathrm{~g}$ de proteína bruta microbiana no abomaso. A redução do NDT da dieta verificada no presente trabalho reduz a produção de proteína microbiana e, com base neste raciocínio, pode-se estimar a produção de proteína microbiana, a qual apresentaria variação de 101 a $81 \mathrm{~g} / \mathrm{dia}$, respectivamente, para as dietas com zero e $28 \%$ de caroço de algodão.

A proteína microbiana é a principal fonte de proteína metabolizável para os animais ruminantes, uma vez que fornece de 50 a $90 \%$ da proteína metabolizável (NRC, 2001), e ainda apresenta elevado valor biológico. Desta forma, a redução de sua síntese no rúmen pode impactar profundamente o desempenho animal.

Cunha et al. (2008), ao trabalharem com ovinos confinados, alimentados com dietas que continham níveis crescente de caroço de algodão integral, diferentemente, não constataram efeitos dos níveis $(0 ; 20 ; 30$ e $40 \%)$ de caroço de algodão na dieta sobre a digestibilidade da MS (64,48\%), MO (69,87\%) e CT $(67,05 \%)$ e, adicionalmente, obtiveram aumento da digestibilidade da FDN com o incremento dos níveis de caroço de algodão. Semelhante ao que foi observado no presente trabalho houve aumento na digestibilidade do EE com o aumento dos níveis de caroço de algodão.

Os resultados relativos à digestão da FDN observados por Cunha et al. (2008) carecem de explicação e são também diferentes dos observados por Rogério et al. (2004) e Teixeira \& Borges (2005), que observaram redução da digestão da FDN e FDA com o incremento dos níveis de caroço de algodão na dieta, comportamento este semelhante ao verificado neste estudo. Pois, no presente trabalho, foi observado que cada $1 \%$ de caroço de algodão incluso à dieta fez reduzir a digestão da FDN em 0,3933 unidades percentuais.

Existem duas hipóteses relativas ao efeito inibitório dos lipídeos sobre a digestão da fibra no rúmen. $\mathrm{Na}$ primeira, os lipídeos, notadamente os insaturados, por se ligarem à superfície vegetal funcionariam como uma barreira, o que limitaria a aderência e a atividade digestiva da microbiota ruminal sobre as partículas de alimento no rúmen Palmquist \& Mattos (2006). $\mathrm{Na}$ segunda, é sugerido que os ácidos graxos insaturados apresentam efeito tóxico sobre a microbiota ruminal. Como resultado de um evento ou outro, a redução da digestão da fibra parece ser o resultado final esperado, o que pode ajudar a explicar o que ocorreu no presente trabalho. Para Palmquist \& Mattos (2006), a vantagem da utilização 
Rev. Bras. Saúde Prod. Anim., Salvador, v.13, n.1, p.110-122 jan/mar, 2012 http://www.rbspa.ufba.br ISSN 15199940

de lipídios em dietas deve-se ao incremento da densidade calórica da dieta, em razão de seu elevado valor energético (aproximadamente 6Mcal $\mathrm{EL} / \mathrm{kg} \mathrm{MS}$ ), vantagem que pode ser explorada de várias maneiras, além de permitir aumento no consumo de energia e balanço mais adequado entre carboidratos estruturais e nãoestruturais para a otimização do consumo de fibra e energia digestível.

Cada $1 \%$ de caroço de algodão acrescentado à dieta promoveu aumento no valor do $\mathrm{pH}$ em 0,00905 e 0,01228 para os tempos zero e quatro horas, respectivamente (Tabela 5), o que pode ser explicado devido ao fato de que as dietas que continham maiores quantidades de caroço de algodão possuíam uma maior quantidade de FDN em sua composição. Desta maneira, o animal pode despender maior tempo com a atividade de ruminação.

O maior teor de FDN nas dietas com incremento nas quantidades de caroço de algodão ajuda a manter o $\mathrm{pH}$ ruminal mais elevado, em decorrência da taxa de digestão mais lenta desta fração no rúmen, comparado àquela dos $\mathrm{CNF}$, com isso é gerada menor concentração total de ácidos graxos voláteis por unidade de tempo, bem como ao efeito da FDN sobre o estímulo à ruminação e secreção de saliva.

Tabela 5. Valores médios obtidos para o pH ruminal e concentração de amônia ruminal (NAR) em função dos níveis de caroço de algodão na dieta

\begin{tabular}{|c|c|c|c|c|c|c|c|c|}
\hline \multirow{2}{*}{ Variável } & \multicolumn{5}{|c|}{ caroço de algodão na dieta (\% MS) } & \multirow{2}{*}{$\mathrm{P}$} & \multirow{2}{*}{ EPM } & \multirow{2}{*}{$\mathrm{R}^{2}$} \\
\hline & 0 & 7 & 14 & 21 & 28 & & & \\
\hline $\mathrm{pH}_{\text {zero }}$ hora $^{1}$ & 6,42 & 6,36 & 6,58 & 6,55 & 6,64 & 0,0391 & 0,05 & 0,72 \\
\hline $\mathrm{pH}_{4}$ horas $^{2}$ & 5,73 & 5,78 & 5,88 & 6,02 & 6,04 & 0,0060 & 0,06 & 0,96 \\
\hline NAR zero hora ${ }^{3}$ & 12,56 & 13,68 & 9,03 & 10,36 & 7,49 & 0,0327 & 1,13 & 0,71 \\
\hline NAR 4 horas $^{4}$ & 20,75 & 16,38 & 13,26 & 14,49 & 11,30 & 0,0014 & 1,61 & 0,84 \\
\hline
\end{tabular}

Para as concentrações de NAR foi observado efeito linear $(\mathrm{P}<0,01)$, para cada $1 \%$ de caroço de algodão na dieta houve decréscimo de $0,1925 \mathrm{mg} / \mathrm{dL}$ e $0,2970 \mathrm{mg} / \mathrm{dL}$, para os tempos zero e quatro horas após a alimentação. Mesmo as dietas sendo isoproteicas, com $22 \pm 1 \%$ de PB, aquelas com menores inclusões de caroço de algodão proporcionaram maiores concentrações de NAR. Isso se deve ao fato de que, mesmo que o caroço de algodão seja considerado um alimento proteico, para que o animal aproveite a sua proteína se faz necessária a exposição do conteúdo presente no interior do grão. Para isso, é necessária a mastigação e ruminação deste grão oleaginoso o que aumenta a superfície específica para $\mathrm{o}$ ataque microbiano. Neste trabalho, o grão foi fornecido inteiro, o que explica as menores concentrações de NAR.

Além disso, no momento da coleta das sobras dos alimentos fornecidos era nítida a maior proporção do caroço de algodão nas sobras para as dietas 
Rev. Bras. Saúde Prod. Anim., Salvador, v.13, n.1, p.110-122 jan/mar, 2012 http://www.rbspa.ufba.br ISSN 15199940

com maiores níveis deste ingrediente. Isso, possivelmente se deu por uma maior seletividade dos borregos, que não ingeriram o caroço de algodão em sua plenitude, o que acarretou em redução do consumo de $\mathrm{PB}$ e, consequentemente, em redução da concentração de NAR. Esse fato pode reduzir a síntese de proteína microbiana, notadamente na dieta com $30 \%$ de caroço de algodão, na qual o NAR manteve-se abaixo de $10 \mathrm{mg} / \mathrm{dL}$, valor mínimo sugerido por Sampaio et al. (2010) e Souza et al. (2010), para garantir adequado crescimento microbiano no rúmen em condições tropicais.

Paralelamente, o decréscimo na concentração amoniacal pode, ainda, estar relacionado à redução da proteólise associada à menor atividade dos microorganismos quando expostos às maiores concentrações de EE na dieta.

Observou-se diferença no peso corporal final (PCF) e ganho médio diário (GMD) para os níveis zero, 10, 20 e $30 \%$ da conversão alimentar na dieta, em que foram constatados 41,$78 ; 41,54$; 39,75 e $36,94 \mathrm{~kg}$ e $238,229,189$ e $144 \mathrm{~g} /$ dia, respectivamente (Tabela 6). Desta forma, cada $1 \%$ de inclusão da conversão alimentar na dieta promoveu redução linear $(\mathrm{P}<0,05)$ do GMD dos animais em $3,208 \mathrm{~g}$.

Tabela 6. Peso corporal inicial (PCI), peso corporal final (PCF), ganho de peso total (GPT) e ganho médio diário (GMD) e tempo que os animais levaram para adquirem $40 \mathrm{~kg}$ de peso vivo (D40) em função dos níveis de caroço de algodão na dieta

\begin{tabular}{lcccccccc}
\hline \multirow{2}{*}{ Variável } & \multicolumn{9}{c}{ Caroço de algodão na dieta $(\% \mathrm{MS})$} & \multirow{2}{*}{$\mathrm{P}$} & EPM & \multirow{2}{*}{$\mathrm{R}^{2}$} \\
\cline { 2 - 5 } & 0 & 10 & 20 & 30 & & & \\
\hline PCI $(\mathrm{kg})$ & 27,50 & 27,81 & 28,39 & 28,29 & - & 0,19 & - \\
PCF $(\mathrm{kg})$ & 41,78 & 41,54 & 39,75 & 36,94 & - & 1,00 & - \\
GPT $(\mathrm{kg})$ & 14,28 & 13,73 & 11,36 & 8,65 & 0,040 & 1,15 & 0,80 \\
GMD $(\mathrm{g})^{2}$ & 238 & 229 & 189 & 144 & 0,035 & 19,22 & 0,85 \\
D40 (dias) & 56,70 & 57,60 & 66,70 & 88,26 & - & 6,56 & - \\
\hline CMS & 1,18 & 1,14 & 1,18 & 1,07 & - & 0,02 & - \\
\hline Conversão alimentar & 5,07 & 5,08 & 6,34 & 7,55 & - & 0,53 & - \\
\hline
\end{tabular}

${ }^{1} \hat{\mathrm{Y}}=42,45-0,163 * \mathrm{CA} ;{ }^{2} \hat{\mathrm{Y}}=248,17-3,208^{*} \mathrm{CA}$.

$\mathrm{P}=$ probabilidade, $\mathrm{EPM}=$ erro padrão da média

A redução na digestibilidade dos nutrientes teve como consequência a queda do desempenho dos animais suplementados com maiores níveis da conversão alimentar. A redução da digestibilidade dos nutrientes (PB, CT e FDN) proporcionou redução no NDT das dietas com maiores níveis da conversão alimentar. Desta forma, menos energia foi proporcionada aos animais à medida que aumentou o nível da conversão alimentar na dieta. Podese também inferir que menos proteína microbiana foi sintetizada no rúmen, o que pode ter contribuído para a redução do desempenho dos animais, uma vez que que a proteína oriunda da microbiota ruminal representa a principal fonte de aminoácidos 
Rev. Bras. Saúde Prod. Anim., Salvador, v.13, n.1, p.110-122 jan/mar, 2012 http://www.rbspa.ufba.br ISSN 15199940

disponíveis para absorção no intestino delgado dos animais.

Ao se considerar que de acordo com o NRC (2001), cada $1 \mathrm{~kg}$ de NDT ingerido possibilita um fluxo de $130 \mathrm{~g}$ de proteína microbiana para o abomaso, com base nos dados de consumo de matéria seca observados neste estudo $(1,18 ; 1,14$; 1,18 e $1,07 \mathrm{~kg} /$ animal $/$ dia) e teores de NDT das dietas obtidos no experimento de digestibilidade (Y NDT $=74,75-$ $0,3909 * \mathrm{CA}$ ), pode-se estimar um fluxo decrescente de proteína microbiana no abomaso, de 115; 105; 103 e 88g/dia, respectivamente, com o aumento dos níveis de caroço de algodão na dieta.

Como observado na Tabela 6 o menor desempenho é reflexo da conversão alimentar dos animais, pois à medida que aumentava a inclusão da conversão alimentar, aumentava a $\mathrm{CA}$, que variou de 5,07 a $7,55 \mathrm{~kg}$ respectivamente, para o nível zero e $30 \%$ de inclusão do caroço de algodão.

Tais resultados podem ser explicados pelo aumento no teor de lipídeos das rações, que no caso dos dois últimos níveis da conversão alimentar ultrapassava $6 \%$ de lipídeos na dieta total. Palmquist \& Mattos (2006) destacaram que os efeitos negativos dos lipídeos se acentuam a partir de tal nível, e essa interferência no metabolismo ruminal é fortemente vinculada à quantidade e ao tipo de lipídio ingerido, às taxas de lipólise e de biohidrogenação ruminal e formação de sais carboxilados no rúmen.

$\mathrm{O}$ consumo médio diário de $\mathrm{MS}$ observado no presente experimento de $1,14 \mathrm{~kg} /$ animal $/$ dia (experimento de desempenho), está próximo ao valor estimado pela equação apresentada por Cabral et al. (2008), de $1,12 \mathrm{~kg} /$ animal $/$ dia, o que permite inferir que a equação sugerida pelos referidos autores apresenta adequada exatidão.
Sugere-se a inclusão de caroço de algodão na dieta de ovinos em confinamento até o nível de $10 \%$.

\section{REFERÊNCIAS}

BERCHIELLI, T.T.; ANDRADE, P.; FURLAN, C.L. Avaliação de indicadores internos em ensaios de digestibilidade. Revista Brasileira de Zootecnia, v.29, n.3, p.830-833, 2000.

CABRAL, L.S.; VALADARES

FILHO, S.C.; DETMANN, E. Consumo e digestibilidade dos nutrientes em bovinos alimentados com dietas à base $\mathrm{e}$ volumosos tropicais. Revista Brasileira de Zootecnia, v.35, n.6, p.2406-2412, 2006.

CABRAL, L.S.; NEVES, E.M.O.; ZERVOUDAKIS, J.T.; ABREU, J.G.; RODRIGUES, R.C.; SOUZA, A.L.; OLIVEIRA, I.S. Estimativas dos requisitos nutricionais de ovinos em condições brasileiras. Revista

Brasileira de Saúde e Produção Animal [Online], v.9, n.3, p.529-542, 2008.

CAVALCANTE, M.A.B.; PEREIRA, O.G.; VALADARES FILHO, S.C. Níveis de proteína bruta em dietas para bovinos de corte: consumo, digestibilidade total e desempenho produtivo. Revista Brasileira de Zootecnia, v.34, n.3, p.711-719, 2005.

CARVALHO, G.G.P; PIRES, A.J.V; SILVA, F.F., VELOSO, C.M.; SILVA, R.R.; SILVA, H.G.O; BONOMO, P.; MENDONÇA, S.S. Comportamento ingestivo de cabras leiteiras alimentadas com Farelo de cacau ou torta de dendê. Pesquisa Agropecuária Brasileira, v.39, n.9, p.919-925. 2004. 
Rev. Bras. Saúde Prod. Anim., Salvador, v.13, n.1, p.110-122 jan/mar, 2012 http://www.rbspa.ufba.br ISSN 15199940

CUNHA, M.G.G.; CARVALHO, F.F.R.; VÉRAS, A.S.C.; BATISTA, A.M.V. Desempenho e digestibilidade aparente em ovinos confinados alimentados com dietas contendo níveis crescentes de caroço de algodão integral. Revista Brasileira de Zootecnia, v.37, n.6, p.1103-1111, 2008 .

COMPANHIA NACIONAL DE ABASTECIMENTO - CONAB. Brasília. 2009. Disponível em: $<$ www.conab.gov.br>. Acesso em: 18 dez. 2009.

NATIONAL RESEARCH COUNCIL NRC. Nutrients requirements of dairy cattle. 7.rev.ed. Washinton, D.C., 2001. $381 \mathrm{p}$.

OLIVEIRA, R.L.; BAGALDO, A.R.; LADEIRA, M.M.; BARBOSA, M.A.A.F.; OLIVEIRA, R.L.; JAEGER, S.M.P.L. Fontes de lipídeos na dieta de búfalas lactantes: consumo, digestibilidade e N-uréico plasmático. Revista Brasileira de Zootecnia, v.38, n.3, p.553-559, 2009.

PALMQUIST, D.L.; MATTOS, W.R.S. Metabolismo de lipídeos. In: BERCHIELLI, T.T.; PIRES, A.V.; OLIVEIRA, S.G. (Eds.). Nutrição de ruminantes. Jaboticabal: Funep, 2006. p.287-310.

RODRIGUES, M.M.; NEIVA, J.N.M.; VASCONCELOS, V.R.; LOBO, R.N.B.; PIMENTEL, J.C.M.; MOURA, A.A.A.N. Utilização do farelo de castanha de caju na terminação de ovinos em confinamento. Revista Brasileira de Zootecnia, v.32, n.1, p.240-248, 2003.
UNIVERSIDADE FEDERAL DE VIÇOSA - UFV. SAEG - Sistema de análises estatísticas e genéticas. Viçosa, MG, 2001. 301p.

SANTOS, J.W.; CABRAL, L.S.; ZERVOUDAKIS, J.T.; SOUZA, A.L.; ABREU, J.G.; BAUER, M.O. Casca de soja em dietas para ovinos. Revista Brasileira de Zootecnia, v.37, n.11, p. 2049-2055, 2008.

SANTOS, J.W.; CABRAL, L.S.; ZERVOUDAKIS, J.T.; ABREU, J.G.; SOUZA, A.L.; PEREIRA, G.A.C.; REVERDITO, R. Farelo de arroz em dietas para ovinos. Revista Brasileira de Saúde e Produção Animal [Online], v.11, n.1, p.193-201, 2010.

SAMPAIO, C.B.; DETMANN, E.; PAULINO, M.F.; VALADARES FILHO, S.C.; SOUZA, M.A.; LAZZARINI, I.; PAULINO, P.V.R.; QUEIROZ, A.C. Intake and digestibility in cattle fed low-quality tropical forage and supplemented with nitrogenous compounds. Tropical Animal Health and Production, v.42, p.1471-1479, 2010.

SILVA, M.M.C.; RODRIGUES, M.T.; RODRIGUES, C.A.F.; BRANCO, R.H.; LEÃO, M.I.; MAGALHÃES, A.C.M.; MATOS, R.S. Efeito da suplementação de lipídios sobre a digestibilidade e os parâmetros da fermentação ruminal em cabras leiteiras. Revista Brasileira de Zootecnia, v.36, n.1, p.246-256, 2007.

SOUZA, M.A.; DETMANN, E.; LAZZARINI, I., PAULINO, P.V.R., QUEIROZ, A.C. Intake, digestibility and rumen dynamics of neutral detergent fibre in cattle fed low-quality tropical forage and supplemented with nitrogen and/or starch. Tropical Animal Health and Production, v.42, p.1471-1479, 2010. 
TEIXEIRA, D.B.; BORGES, I. Efeito do nível de caroço de algodão integral sobre o consumo e digestibilidade aparente da fração fibrosa do feno de braquiária (Brachiaria decumbes) em ovinos. Arquivo Brasileiro de Medicina Veterinária e Zootecnia, v.57, n.2, p.229-233, 2005.

VAN SOEST, P.J.; ROBERTSON, J.B.; LEWIS, B.A. Methods for dietary fiber, neutral detergent fiber, and nonstarch polysaccharides in relation to animal nutrition. Journal of Dairy Science, v.74, n.10, p.3583-3597, 1991.
VÉRAS, R.M.L.; FERREIRA, M.A.; CAVALCANTI, C.V.A.; VÉRAS, A.S.C.; CARVALHO, F.F.R.; SANTOS, G.R.A.; ALVES, K.S.; SOUTO MAIOR JR, R.J. Substituição do milho por farelo de palma forrageira (Opuntia ficus indica Mill) em dietas de ovinos em crescimento: desempenho.

Revista Brasileira de Zootecnia, v.34, n. 1, p. 249-256, 2005.

Data de recebimento: 13/04/2011

Data de aprovação: 20/12/2011 